tures take over from the text.

For polar specialists this book will revive happy memories: they will wish to give it to their friends. For those coming new to polar studies it is an excellent introduction. (Peter Speak, Scott Polar Research Institute, University of Cambridge, Lensfield Road, Cambridge CB2 1ER.)

\section{ANTARCTIC MINERALS}

ANTARCTIC MINERAL EXPLOITATION. Orrego Vicuña, F. 1988. Cambridge, Cambridge University Press. 615p, hard cover. ISBN 0-521-32383-5. £60.00, US\$89.50.

This is a very comprehensive examination of what probably is currently the most discussed Antarctic subject. The subtitle, 'The Emerging Legal Framework', indicates the evolutionary and developmental nature of the work which examines in detail the large number of aspects in this complicated problem. At present the exploitation of minerals in Antarctica is unlikely for many years but investigation and, in as far as practicable, clarification of the legal basis for such operations prior to their beginning is an essential preliminary. The work will be of interest to international lawyers and others involved in Antarctic affairs, and of importance to the legal advisers of mineral companies.

The work is in three main parts. It starts with an analysis of the beginnings of exploration of Antarctica and the origins of the several national claims which resulted. A note follows on claims of sovereignty, with the development of the Antarctic Treaty which places these in abeyance. The evolution and extention ot the Treaty to adjust to many factors which have arisen in the years since it was written (1959) is described. Similarly a discussion of other aspects of International Law, especially the Law of the Sea, which provide examples and precedents is included.

The second part discusses alternative approaches to conservation and development of Antarctic minerals, with processes of internal accommodation. Conflicting interests and desires are examined with an analysis of the criteria for determining suitable regimes in a quest for an equilibrium between them. This section gives attention to the complexity of interests involved, with discussion of a wide range of subjects that will need analysis. It leads to the third section where the application of the Antarctic Treaty is specifically treated, in particular the present participation of states and relation with the international community. It concludes with a consideration of the future of the Treaty.

The work is characteristically provided with very comprehensive notes and details of sources which make it a useful reference for Antarctic legal studies in general. A series of appendices summarises legal and national situations, and an excellent 54 page bibliography follows. The index is efficiently arranged and a useful guide through a complex subject. (R. K. Headland, Scott Polar Research Institute, Lensfield Road, Cambridge CB2 1ER).

\section{TO THE NORTH POLE}

NORTH TO THE POLE. Steger, Will and Schurke, Paul. 1987. London, Macmillan. 339p, illustrated, hard cover. ISBN 0-333-47490-2. £14.95.

The offical narrative, based on the leader's, co-leader's and other journals, of the Steiger International Polar Expedition 1986; this was a joint U.S.-Canadian-New Zealand enterprise, and one distinguished by its single woman member, Ann Bancroft, who can now claim to be the first woman to sledge to the North Pole. The object of the expedition - much in the spirit of R. E. Peary - was to achieve the Pole 'unsupported', ie aircraft would be used only to evacuate casualties and superflous dogs and equipment. This policy was rigidly adhered to.

The expedition of eight members and 49 dogs left northen Ellesmere Island on 7 March. Going proved heavy in the early stages with heavy pressure and temperatures in the minus seventies Fahrenheit. Later conditions improved, and over 30 miles travel daily was not unusual. Light relief from frostbite and painful drudgery was provided by the occasional visit of a relief plane bearing a media circus of reporters and cameramen (the inevitable price of sponsorship) and a serendipitous meeting with the solo French explorer Jean-Louis Etiene. The pole was achieved on 1 May, the expedition having traversed nearly twice the actual distance of 488 miles due to ice drift relaying and navigational errors. This is a readable account, with much in the appendices and elsewhere of value to any potential assailant of the North Pole. The black and white photography is disappointing, though. (H. G. R.King, Scott Polar Research Institute, University of Cambridge, Lensfield Road, Cambridge CB2 1ER.)

\section{ICE MECHANICS}

ICE MECHANICS: RISKS TO OFFSHORE STRUCTURES. Sanderson, T. J. O. 1988. London, Graham and Trotman. 253 p, illustrated, hard cover. ISBN 0-86010785-X. $£ 75.00$, US\$ 141.00 .

This is abook for which Arctic ice engineers and scientists have been waiting for years. It is the first reference text to deal in a comprehensive way with ice loads on marine structures. It is also written in a clear and attractive style and is a pleasure to read.

Beginning with two chapters of the physical properties and distribution of sea ice and icebergs (which in themselves constitute an excellent text for students of oceanography), the author then deals with the mechanical properties of ice as measured on a laboratory scale and on the full scale. The description of full-scale measurements of ice forces on islands (natural and artificial) and drilling platforms is particularly useful and authoritative, since it 
draws on the author's own experience with BP's work in the Beaufort Sea and summarises the results of many hitherto proprietary studies. It also contains a description of measurement techniques and their application.

Chapter 6 deals with the theoretical analysis of ice failure. Here the reader becomes aware of the gap which still exists between the mathematical analysis of elastic buckling, creep buckling and fracture, and the real behaviour of ice on a large scale. Our lack of knowledge of the ways in which cracks nucleate and propagate is one of the major obstacles. The final chapter, on calculation of design loads, makes use of the earlier material to give advice on the immediate practical problem faced by the ice engineer, that of estimating the maximum load exerted by ice at a given site on a given structural design. Continuous static and dynamic loading are considered, as well as the discontinuous impact forces of isolated multi-year floes and icebergs on a structure.

Everyone concerned with ice problems will find this book of value. The design engineer may start with the last chapter and work his way backwards in order to understand the theoretical and observational underpinnings to the design load calculations recommended. The ice physicist or oceanographer will start with the first two chapters but will read on in fascination at the ways in which the methods of physics and engineering complement one another in the attack on an immensely important practical problem.

The continuation of low oil prices has caused a lull in the development of Arctic resources, but there is no doubt that the Beaufort, Labrador and Barents seas will once again become a main focus for oil exploration. This book will be of the greatest value to everyone involved in that frontier. (Peter Wadhams, Scott Polar Research Institute, University of Cambridge, Lensfield Road, Cambridge CB2 1ER.)

\section{ALASKAN HISTORY IN MAPS}

ALASKA EXPLORATION MAP SERIES. Marshall, Philip S. (compiler and editor). 1987. Fairbanks, University of Alaska Press (Produced by the Arctic Environmental Information and Data Center). 4 maps folding. US $\$ 25.00$ plus US $\$ 2.00 \mathrm{p}$ and $\mathrm{p}$.

In a series of four maps, compiler Philip Marshall shows the routes of sixty expeditions in and around Alaska, from Vitus Bering's maritime voyage of 1728 to the transpolar dirigible flight by Roald Amundsen and Umberto Nobile in 1926. The maps, scaled at one inch to 69 statute miles, summarize two centuries of Euro-American efforts to delineate the coastline, discover a Northwest Passage, chart the rivers and mountain ranges, locate minerals, collect specimens and artifacts, establish communication lines, and Christianize the native inhabitants. The selection of expeditions has been guided by their historical and geographical significance and by the availability of adequate documentation. The result is not an 'exhaustive' representation of Alaskan exploration but a generalized picture intended mainly for secondary school history students.

The large $(2 \times 3 \mathrm{ft})$ maps fold into a paper envelope $(9$ $x 12$ ins). Coloured symbols showing the tracks of expeditions are generally clear, although more arrows indicating direction of travel would be useful. Additional information, sometimes anecdotal and trivial, is provided in approximately 100 boxes, and a number of portraits and small sketches are scattered about. The style resembles that of National Geographic maps, but the execution is not as good. The map envelope contains notes and corrections, and nearly 100 bibliographic sources are listed on the backs of the maps.

With the space available on these large maps latitude and longitude could easily have been indicated, and the areas blanketed by boxes might have been used more effectively by showing some of the major environmental features that have influenced the course of exploration, such as topography, natural vegetation (in particular the tree line separating arctic tundra from subarctic forest), and the seasonal limits of sea ice. The lack of physical information to provide a context for the understanding of the geography of exploration is especially curious, as the maps were produced by a centre of environmental information. Despite this shortcoming the map series constitutes a convenient guide to the Alaska's exploration. (W. Gillies Ross, Scott Polar Research Institute, University of Cambridge, Cambridge CB2 1ER.)

\section{BEAUFORT SEA GEOLOGY AND GEOPHYSICS}

MARINE SCIENCE ATLAS OF THE BEAUFORT SEA; GEOLOGY AND GEOPHYSICS. Pelletier, B.R. (editor). Ottawa, Energy, Mines and Resources Canada, Geological Survey of Canada Miscellaneous Report 40. $43 \mathrm{p}$, illustrated, soft cover. ISBN 0-660-53107-0. Can $\$ 30.00$ in Canada, $\$ 36.00$ in other co0ntries.

This handsome atlas is an outgrowth of the Beaufort Sea Project, begun in 1974-75 by the Canadian government and a segment of the Canadian petroleum industry as a study of the coastal and offshore area of northwestern Canada that has the hydrocarbon potential perhaps equal to that of Prudhoe Bay to the west. More than 40 research projects were conducted on the physical, biological, and human aspects of potential development of oil and gas in this area. More than 60 investigators contributed to this atlas, which contains only topics on geology and geophysics.

The format is large folio $14 \times 20$ ins ( $35.6 \times 50.8 \mathrm{~cm})$, in which each of 38 fold-out plates shows information on the tectonics, seismicity, magnetic setting, gravity anomalies, geothermal gradients, geology, and permafrost zones. All those are in color, and several plates include black- and-white photographs of representative land and geologic features. Each plate includes explana- 